\title{
Analysis of the Multi-Relationships and Their Structures for Safety Culture
}

\author{
Teh-Sheng Su ${ }^{1}$, Pei-Ru Lin ${ }^{2}$, Yi-Liang Shu ${ }^{1}$, Jo-Ming Tseng ${ }^{3}$, Chen-Shan Kao ${ }^{2^{*}}$ \\ ${ }^{1}$ Department of Safety, Health and Environmental Engineering, Central Taiwan University of Science and Technology, \\ Taichung, Chinese Taipei \\ ${ }^{2}$ Department of Safety, Health and Environmental Engineering, National United University, Miaoli, Chinese Taipei \\ ${ }^{3}$ Institute of Safety and Disaster Prevention Technology, Central Taiwan University of Science and Technology, \\ Taichung, Chinese Taipei \\ Email: jcsk@nuu.edu.tw
}

Received June 14, 2012; revised July 20, 2012; accepted August 5, 2012

\begin{abstract}
Studies on safety culture and safety performance have been increasing recently and several proposed models have been developed and evaluated to identify their key dimensions. However, many studies focus more on measuring the scales of the safety culture and safety performance dimensions. This study aims to seek a deeper understanding of the overall structures of safety culture, safety performance and their relationships by using exploratory and confirmatory factor analysis along with the structural equation modeling (SEM) statistical technique, because the above-mentioned concepts and technique have been seldom employed and are uncommon in manufacturing companies, in terms of Taiwan. We first carry out a thorough literature review and propose an integrated model of safety culture and safety performance with eight dimensions and four dimensions, respectively. We then state a series of hypotheses and test the proposed model on a sample of 370 valid data from three manufacturing companies in Taiwan. Results show that the third-order safety culture associated with second-order safety performance model turns out to be the desired model, where both the measured variables and latent variables have good reliability. The proposed model meets many criteria of the goodness of fit as well.
\end{abstract}

Keywords: Safety Culture; Safety Performance; Structure Equation Modeling

\section{Introduction}

Occupational safety and health management is an efficient way to increase industrial safety. People recognize how to improve on the limitations of health and safety problems by improving the technique and hardware. Adopting a safety work system and establishing work safety rules could improve the safety and health conditions, but some people do not obey the rules during the work period; therefore, efficiency is still limited. Many companies try to improve their safety and health conditions by three stages. The first one is the technique improving stage. This stage is comprised of engineering improvement, renewing of machines, engineering control systems, ventilation systems, and using PPE, etc. The second is the stage of improving the safety and health system; improving occupational safety and health only by controlling the hazard factors is not enough. Therefore, a safety management system is employed to establish a safety policy and safety structure to improve the safety performance by staff participation. However, safety man-

"Corresponding author. agers realized that improving safety and health by the previous stages is not enough; The last stage is created, as so-called safety culture. This safety culture could be employed to improve the safety performance in companies. Safety culture and performance are both important ways to increase the degree of safety and health in an extensive work environment. Safety behavior can be improved by establishing a safety culture, even safety performance and degree of safety. Evaluation of safety performance has the following benefits: understanding the risk degree of safety and health, continuing improvement of the system, increasing the efficiency and potency of organizational communication, distributing the resource, and finding the basic problems of safety and health, etc.

Safety performance [1] is defined as the overall performance of the organization safety management system in safe operation [2], and which is divided into three types [3]. Safety culture is defined through the sharing the safety concepts, safety attitude, safety opinions, and safety behavior in each staff regarding the policy of lessening exposure risk, way of doing, procedure, and so on for preventing accidents and diseases from occurring. 
Though many safety culture models have been developed and tested by various researchers in an attempt to identify the key dimensions of safety culture [4-14], an overall structure of safety culture and safety performance and their relationship are still undeveloped. Only until recently applications of the structure equation modeling (SEM) to identify the structure of safety management, safety climate and firm performance have been proposed and assessed [15-20]. Concepts and techniques were seldom applied in manufacturing companies. This study with a view based on the previous studies [21-24] is to integrate and construct an overall structure of the safety culture and safety performance model and then to utilize SEM techniques to test if the theoretically driven structure of the proposed model will be reflected in the data.

\section{Methods}

\subsection{SEM}

SEM is a statistical method for testing and estimating causal relationships with the combination of statistical data and qualitative causal assumptions. It is more like a confirmatory factor analysis (CFA) technique, rather than an exploratory factor analysis (EFA) technique, i.e., using SEM to determine whether a certain model is valid to find a suitable model, although SEM analyses often involve certain exploratory elements. We start with a hypothesis, represent it as a model, and use confirmatory factor analysis to measure the patterns and confirm whether the observed variables can be effectively explained by the latent variables. Then we test the potential causal relationship between variables by comparing the estimated matrices representing the relationships between variables in the model to the actual matrices. To perform the analysis, the constructed safety culture and safety performance models were submitted to a confirmatory factor analysis using the Amos17.0 software program.

\subsection{Assessment of Fit}

There are more than ten of measures of fit, and in this study we used Goodness of Fit Index (GFI), Adjusted Goodness of Fit Index (AGFI), Comparative Fit Index (CFI), Root Mean Residual (RMR), Root Mean Square Error of Approximation (RMSEA), and Normed ChiSquare $\left(\chi^{2} / \mathrm{d} f\right)$ to determine the overall goodness of fit to the sample data. Their acceptable criteria are listed in Table 1. The Amos program provides multiple indices to ascertain the model fit. It is appropriate to present a selection of various fit measures since different measures of fit capture different elements of the fit of the model.

\subsection{The Models}

To perform the analysis, the following safety culture and performance models are assumed, constructed and accessed:

1) Null model: usually used as a baseline model assuming that safety culture and performance model do not have any common factor existing and hence all the observed variables are mutually independent.

2) First-order single factor model: assuming that all the observed variables are not mutually independent and instead having one common factor.

3) Second-order single factor model: similar to firstorder correlated multi-factor model; it further assumes that all the first-order factors can be explained by a common factor with higher order.

4) Second-order multi-factor model: further assuming that instead of having a single second-order factor, a correlated multi-factor will be appropriated.

5) Third-order single factor model: the highest order this study approached.

The overall safety culture and safety performance questionnaire consists of 103 items that are associated with eight global factors for safety culture and four global factors for safety performance, respectively. For safety culture the following were specified: commitment \& support (CS), communication \& involvement (CI), training \& competence (TC), supervision \& audit (SA), management system \& organization (SO), accident investigation \& emergency response (AE), attitude \& behavior (AB), reward and punishment \& benefits (RB) were specified. For safety performance the following were identified: workplace safety organization (WSO), workplace safety management (WSM), workplace safety control (WSC), workplace safety behavior (WSB).

\section{Results and Discussions}

The results of this analysis are presented in Table 2 and Figures 1-4. Systematic testing of series of first-, second-, and third-orders of correlated and uncorrelated factors models were performed. The research hypothesis of this study was as follows for demonstrating and discussing: 1) Safety culture can be composed of eight dimensions which are correlated; 2) The eight dimensions of safety culture can be explained with dimensions of a

Table 1. Measures of fit and their criteria (Baumgarther et al., 1996).

\begin{tabular}{cc}
\hline Measures of fit & Acceptable criterion \\
\hline GFI & $>0.9$ or $>0.8$ \\
AGFI & $>0.9$ or $>0.8$ \\
RMR & $<0.05$ \\
RMSEA & $<0.08$ \\
CFI & $>0.9$ \\
$\chi^{2} / \mathrm{d} f$ & $<2$ or $<3$ \\
\hline
\end{tabular}




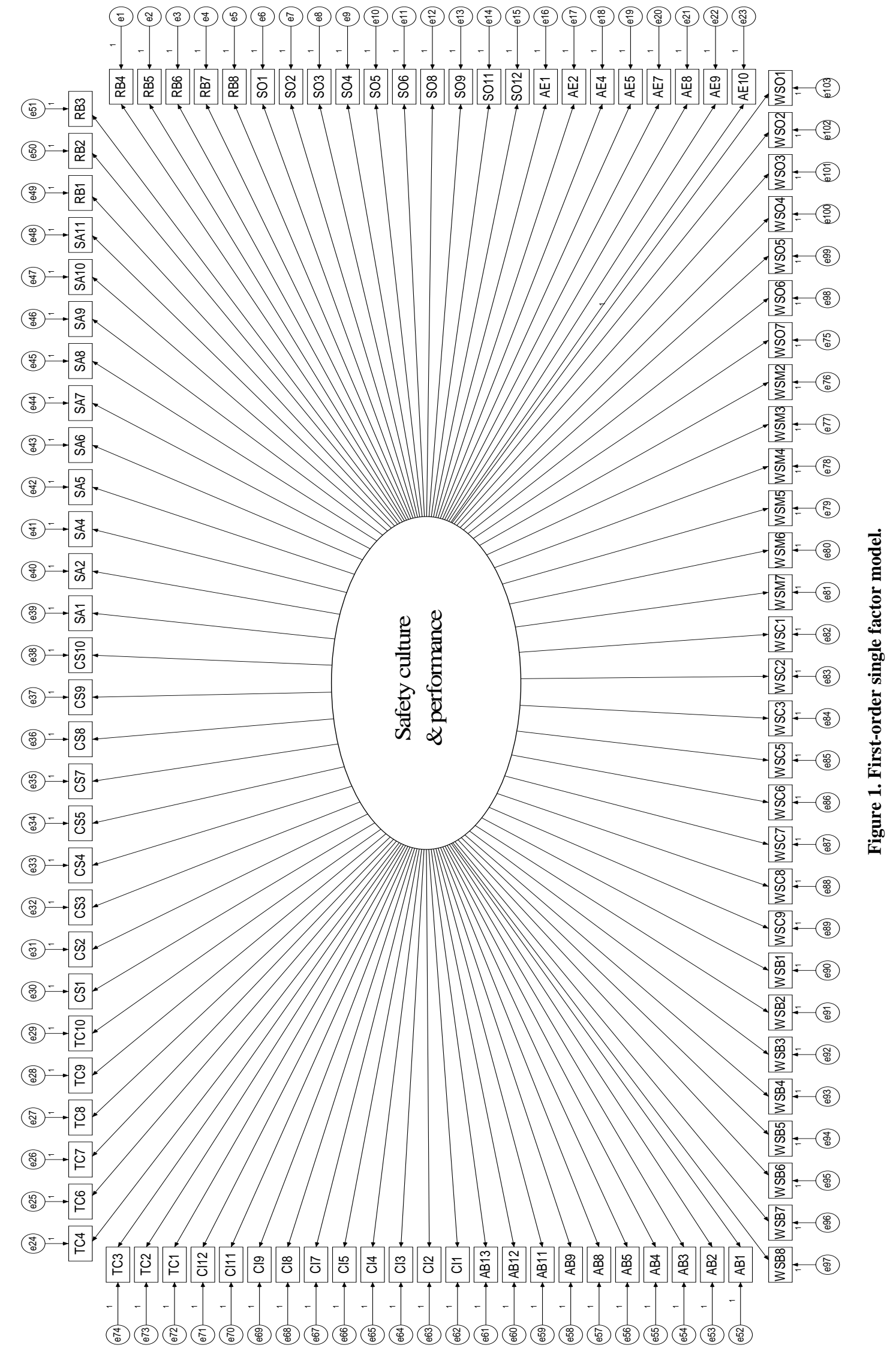




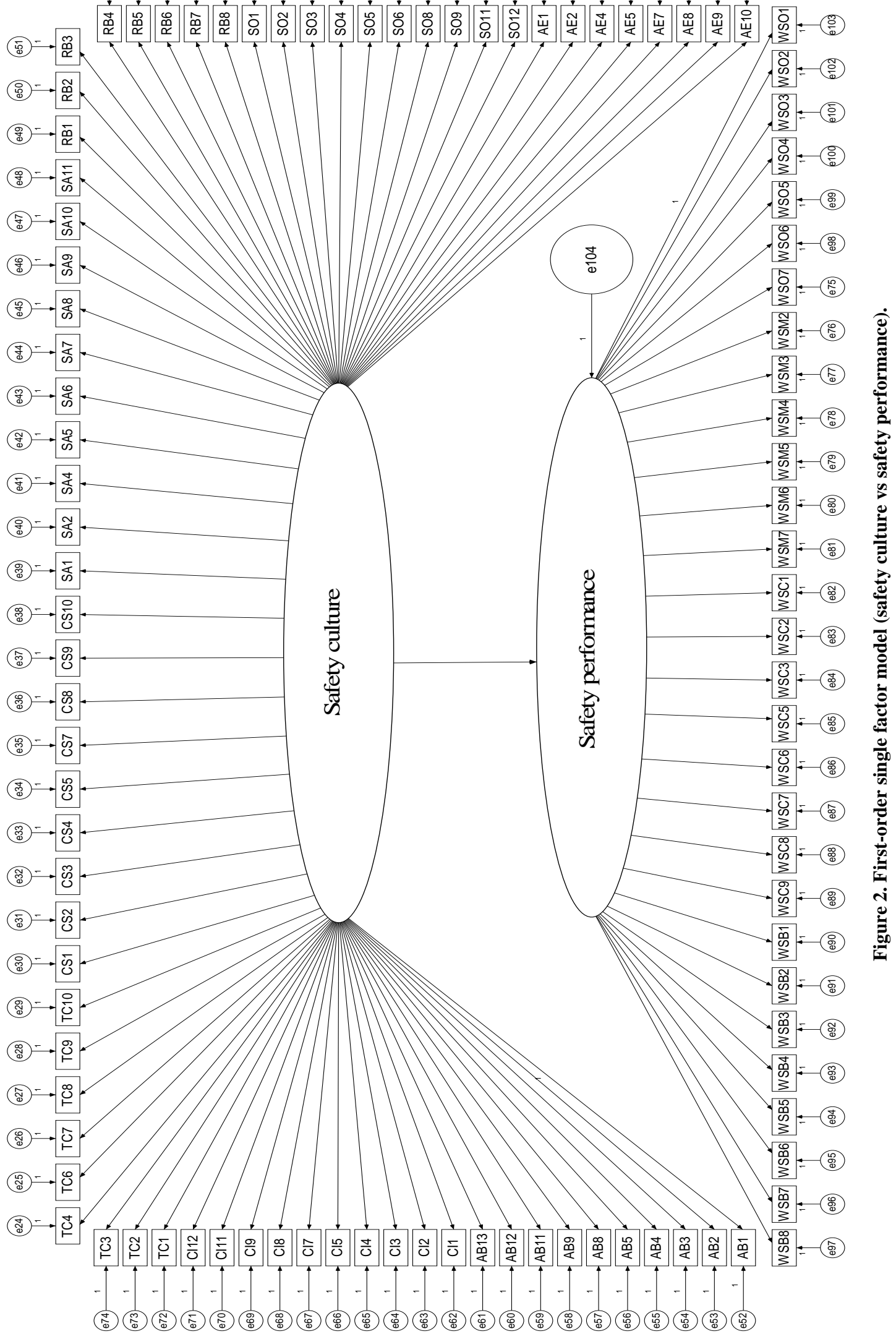




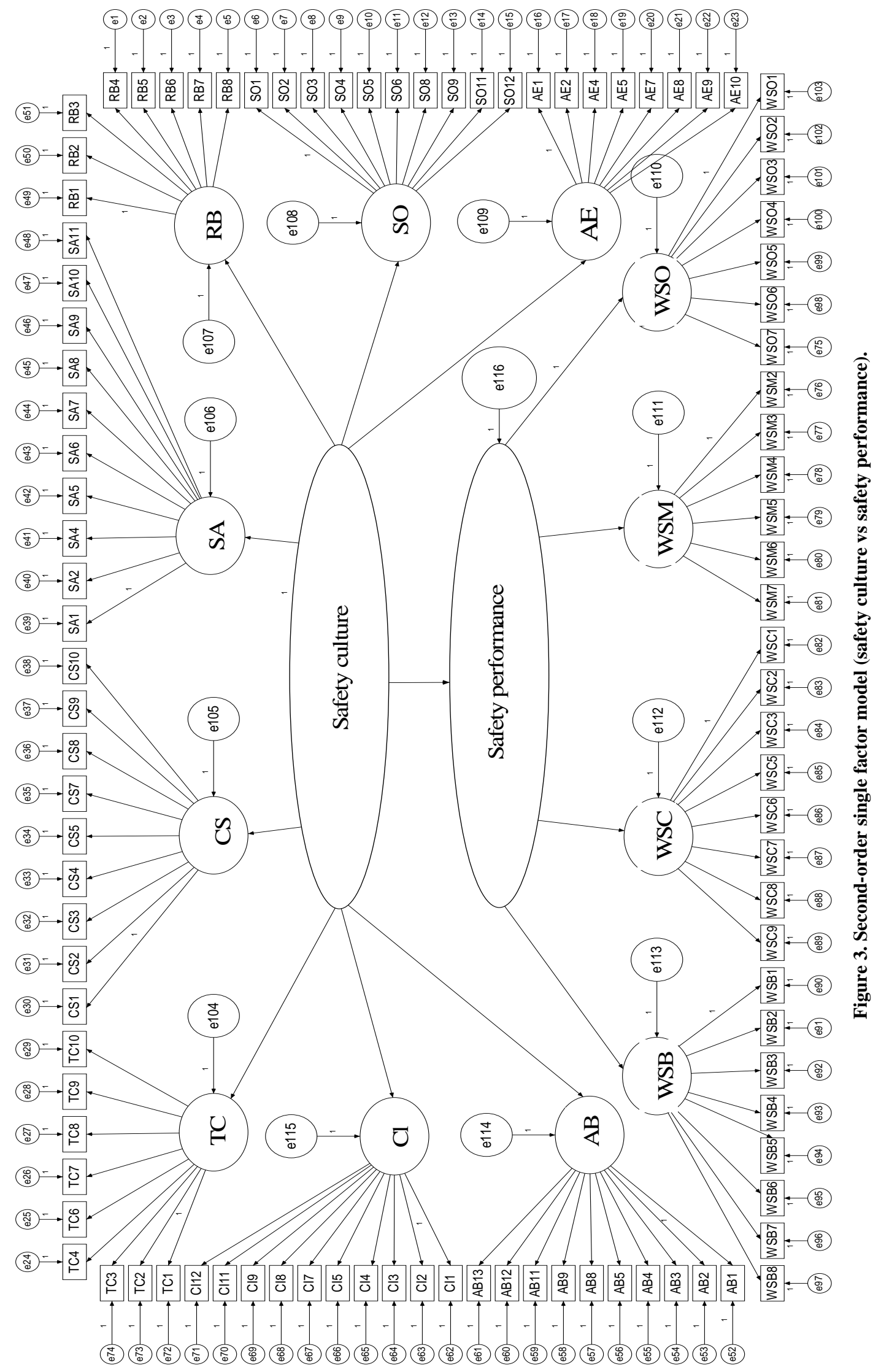




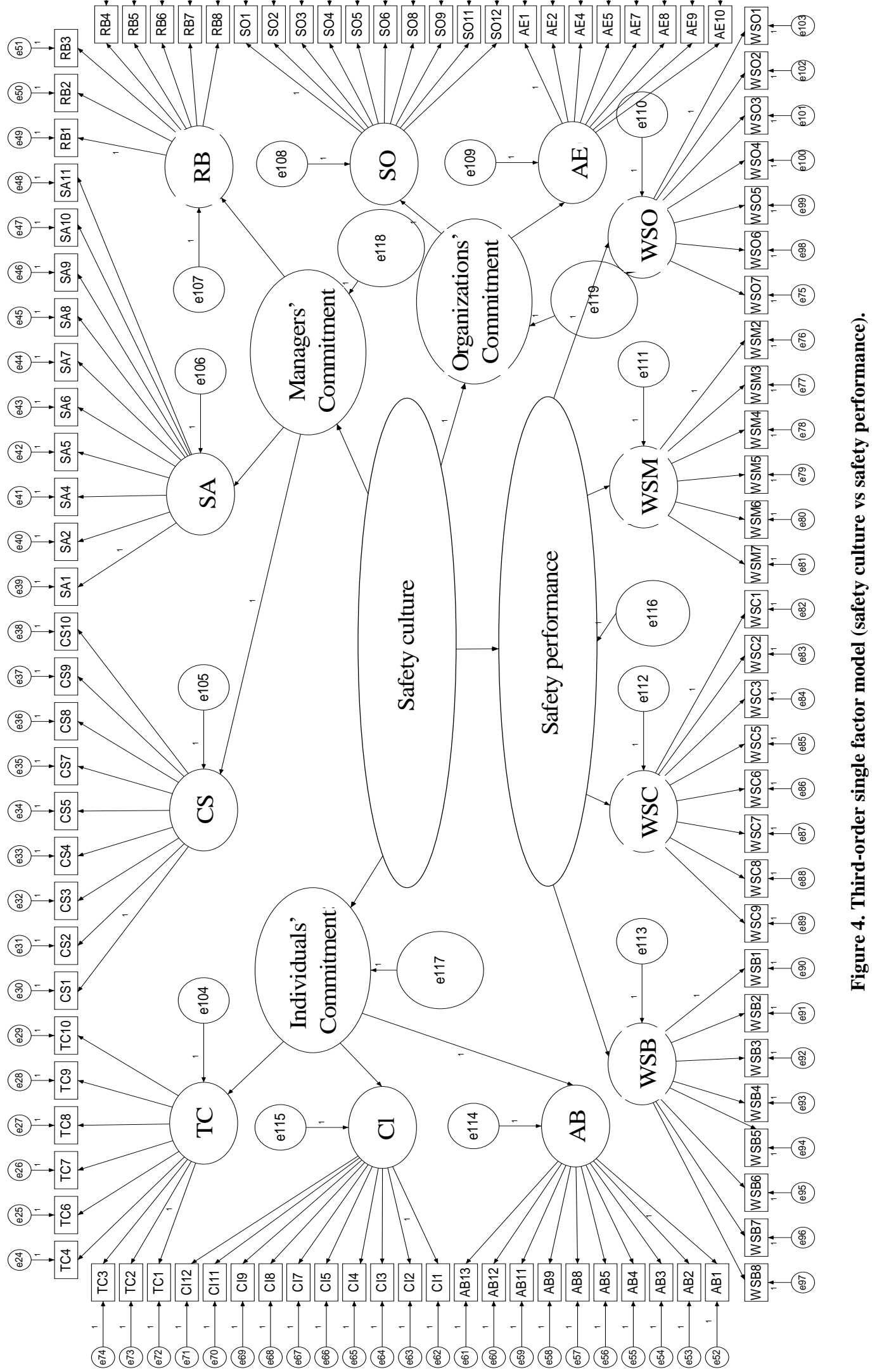


Table 2. Summary of overall measures of fit.

\begin{tabular}{ccccccc}
\hline \multirow{2}{*}{ Model } & \multicolumn{5}{c}{ Overall measures of fit } \\
\cline { 2 - 7 } & GFI & AGFI & RMR & RMSEA & CFI & $\chi^{2} / \mathrm{d} f$ \\
\hline Null model & 0.034 & 0.015 & 0.403 & 0.145 & 0.000 & 8.876 \\
$\quad$ First order single factor model & 0.332 & 0.305 & 0.049 & 0.083 & 0.679 & 3.547 \\
$\begin{array}{c}\text { First order single factor model } \\
\text { (safety culture vs safety performance) }\end{array}$ & 0.484 & 0.464 & 0.043 & 0.073 & 0.755 & 2.948 \\
$\begin{array}{c}\text { Second order single factor model } \\
\text { (safety culture vs safety performance) } \\
\text { Third order single factor model }\end{array}$ & 0.568 & 0.550 & 0.042 & 0.061 & 0.826 & 2.386 \\
(safety culture vs safety performance) & 0.569 & 0.551 & 0.041 & 0.061 & 0.828 & 2.371 \\
\hline
\end{tabular}

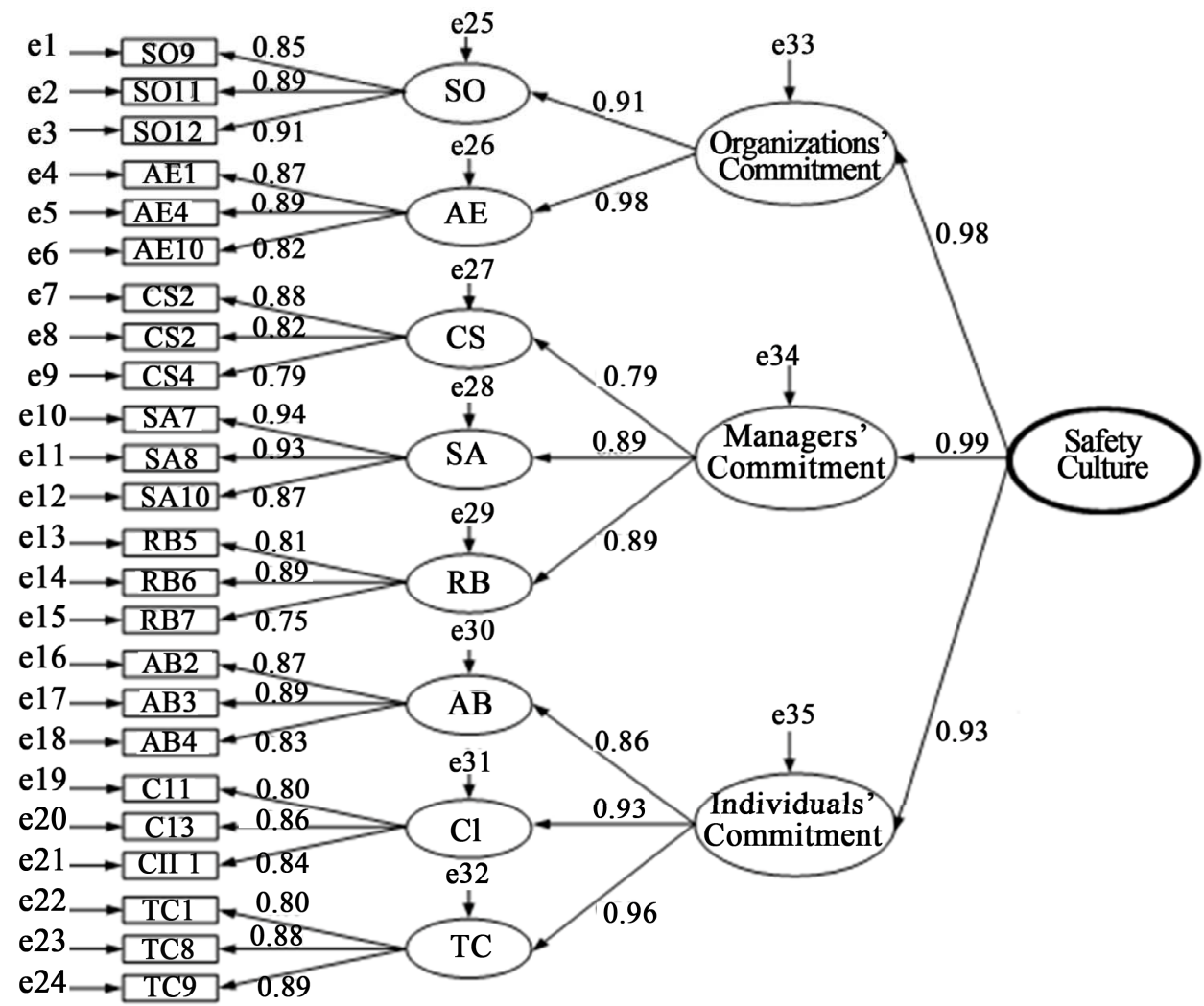

Figure 5. Third-order single factor model (safety culture) with 36 items.

higher level; 3) Safety performance is composed of four correlated dimensions; 4) The four dimensions of safety performance can be explained with dimensions of a higher level. From Table 2 and Figure 4 we can see that the third-order single factor of safety culture vs the secondorder single factor of the safety performance model fitted the data well. That is, the eight global factors represent the first-order factors; organization, managerial, and individual commitments as the second-order factors; and the safety culture as the third-order factor; four global factors represented the first-order factors and safety performance as the second-order factor of the safety performance. However as shown in Table 2 the GFI and AGFI are far from being acceptable.
One way to analyze the model more effectively is to reduce the total of 103 items to a reasonable degree. To do this, the following requirements were applied:

1) To assure model consistency all factors are considered equally important such that each factor will remain 4 or 3 items. That is, model with total of 48 items and 36 items, respectively.

2) Cronbach's alpha coefficients of each of the twelve factors must be greater than 0.8 .

3) The loading factors of all selected items must be greater than 0.7 .

4) All the acceptable criteria of the measures of fit in Table 1 must be achieved.

Finally, 36 items with a maximum overall alpha value 
Table 3. Overall measures of fit with reduced items.

\begin{tabular}{cccccccc}
\hline \multirow{2}{*}{$\begin{array}{c}\text { Third-order singlefactor model } \\
\text { (safety culture vs safety performance) }\end{array}$} & GFI & AGFI & RMR & RMSEA & CFI & $\chi^{2} / \mathrm{d} f$ \\
\hline With 48 items & 0.780 & 0.757 & 0.031 & 0.057 & 0.932 & 2.218 \\
With 36 items & 0.845 & 0.822 & 0.028 & 0.053 & 0.958 & 2.018 \\
\hline
\end{tabular}

of 0.980 were obtained and satisfied all the measures of fit as shown in Table 3. The extremely high Alpha values of all factors assured that the underlying structure of the factors was appropriate. The third-order safety culture model was constructed. The final model is presented in Figure 5. It can be shown that the model is excellent since all the standardized path coefficients are greater than 0.7 .

\section{Conclusion}

Proposed safety culture and safety performance models were constructed, tested, and verified. Results showed that the third-order single factor safety culture vs secondorder single factor safety performance model is the desired model where the measures of fit are fulfilled and both of the observed variables and latent variables have good reliability.

\section{Acknowledgements}

We are indebted to the sponsor of the National Science Council in Taiwan for supporting this research project.

\section{REFERENCES}

[1] F. Wegman and S. Oppe, "Benchmarking Road Safety Performances of Countries," Safety Science, Vol. 48, No. 9, 2010, pp. 1203-1211. doi:10.1016/j.ssci.2010.02.003

[2] T. C. Wu and C. L. Kang, "A Study on the Survey of Safety Performance Perceived by the Workers of in the Four Types of Manufacturing Industry in Taiwan,” Journal of Occupational Safety and Health, Vol. 12, No. 1, 2004, pp. 73-90.

[3] S. S. Wei, "A Study of Implementation of Safety Performance Management,” Industrial Safety Technology Quarterly, Vol. 66, 2008, pp. 7-10.

[4] R. Carl, "Can Focus on Safety Culture Become an Excuse for Not Rethinking Design of Technology?” Safety Science, Vol. 48, No. 2, 2010, pp. 268-278. doi:10.1016/j.ssci.2009.07.008

[5] A. Ahmet and K. Sytze, "Safety Culture in an Aircraft Maintenance Organisation: A View from the Inside,” Safety Science, Vol. 49, No. 2, 2011, pp. 268-278. doi:10.1016/j.ssci.2010.08.007

[6] T. O. Nævestad, "Evaluating a Safety Culture Campaign: Some Lessons from a Norwegian Case,” Safety Science, Vol. 48, No. 5, 2010, pp. 651-659.

doi:10.1016/j.ssci.2010.01.015
[7] INSAG, "Safety Culture. Safety Reports Series No. 75INSAG-4,” International Atomic Energy Agency, Vienna, 1991.

[8] E. S. Geller, “Ten Principles for Achieving a Total Safety Culture,” Professional Safety, September 1994, pp. 18-24.

[9] M. D. Cooper, R. A. Phillips, V. J. Sutherland and P. J. Makin, "Reducing Accidents Using Goal Setting and Feedback: A Field Study,” Journal of Occupational and Organizational Psychology, Vol. 67, No. 3, 1994, pp. 219240. doi:10.1111/j.2044-8325.1994.tb00564.x

[10] S. J. Cox and R. Flin, "Safety Culture; Philosopher's Stone or Man of Straw?” Work \& Stress, Vol. 12, No. 3, 1998, pp. 189-201. doi:10.1080/02678379808256861

[11] Health and Safety Executive, "Development of a Business Excellence Model of Safety Culture,” HSE, Entec UK Ltd., London, 1999.

[12] Health and Safety Executive, "Safety Culture Maturity Model," Offshore Technology Report, HSE, Entec UK Ltd., London, 2000.

[13] P. Hudson, "Understanding Safety Management in the Context of Organizational Culture. NATO/Russia ARW," Forecasting and Preventing Catastrophes Conference, University of Aberdeen, 2-6 June 2003.

[14] M. Iotrowski and D. Hinshaw, "The Safety Checklist Program: Creating a Culture of Safety in Intensive Care Units," Journal on Quality Improvement, Vol. 28, 2002, pp. 306315.

[15] M. C. Mario, G. Francisco, T. Inés and J. M. Peiró, "Leadership and Employees' Perceived Safety Behaviours in a Nuclear Power Plant: A Structural Equation Model,” Safety Science, Vol. 49, 2011, pp. 1118-1129. doi:10.1016/j.ssci.2011.03.002

[16] F. M. Beatriz, M. P. José Manuel and V. O. Camilo José, "Safety Management System: Development and Validation of a Multidimensional Scale," Journal of Loss Prevention in the Process Industries, Vol. 20, No. 1, 2007, pp. 52-68. doi:10.1016/j.jlp.2006.10.002

[17] F. M. Beatriz, M. P. J. Manuel and V. O. C. José, "Safety Culture: Analysis of the Causal Relationships between Its Key Dimensions,” Journal of Safety Research, Vol. 38, No. 6, 2007, pp. 627-641. doi:10.1016/j.jsr.2007.09.001

[18] F. M. Beatriz, M. P. J. Manuel and V. O. C. José, "Relation between Occupational Safety Management and Firm Performance,” Safety Science, Vol. 47, No. 7, 2009, pp. 980-991. doi:10.1016/j.ssci.2008.10.022

[19] S. H. Hsu, C. C. Lee, M. C. Wu and K. Takano, “A Cross-Cultural Study of Organizational Factors on Safety: Japanese vs Taiwanese Oil Refinery Plants," Accident Analysis and Prevention, Vol. 40, No. 1, 2008, pp. 24-34. 
doi:10.1016/j.aap.2007.03.020

[20] S. E. Johnson, "The Predictive Validity of Safety Climate,” Journal of Safety Research, Vol. 38, 2007, pp. 511521. doi:10.1016/j.jsr.2007.07.001

[21] C. S. Kao, P. R. Lin, M. C. Yang, W. H. Lai and T. S. Su, "Identification of Safety Culture Structure and Its Major Factors of the Chemical Industry in Taiwan,” The 24th APOSHO Annual Conference, Seoul, 2008, pp. 123-129.

[22] W. H. Lai, "The Safety Culture Assessment of Petrochemical Industries-Case Study of Five Companies in Tai- wan,” MS Thesis, National United University, Miaoli, 2006.

[23] C. S. Kao, W. H. Lai, T. F. Chuang and J. C. Lee, "Safety Culture Factors, Group Differences, and Risk Perception in Five Petrochemical Plants," Process Safety Progress, Vol. 27, No. 2, 2008, pp. 145-152. doi:10.1002/prs.10246

[24] T. S. Su, "Safety and Health Policy and Intellectual Databank Project,” Institute of Occupational Safety and Health, Taipei, 2007. 